\title{
Foreign OR, Canadian doc: medical tourism with a twist
}

$\mathrm{O}$ rthopedic surgeons in Canada are well aware that people sometimes travel abroad for quicker access to procedures such as hip and knee replacements, but news that Canadian doctors are accompanying patients to exotic locales has caught some by surprise.

"It is an unusual practice to bring the patients with you to a foreign country," says Dr. Edward Harvey, president of the Canadian Orthopaedic Association. "Truthfully, the Canadian Orthopaedic Association was unaware that it was happening."

Recently, it has come to public attention that two surgeons in Calgary, Alberta, have occasionally been flying to the Turks and Caicos to perform joint procedures on Canadian patients. The service is coordinated by Global MedChoices, a company based in Memphis, Tennessee. On the company's website, two surgeons from the United States are also profiled.

"We are not saying that what we are doing is for everybody," says Richard Boddington, chief operating officer of Global MedChoices. "We perceive it as a niche opportunity."

According to Boddington, this form of medical tourism offers several advantages over the traditional model, whereby patients fly to countries such as India or Thailand for operations by local physicians. The biggest is that patients can be confident they are receiving high-quality care from an experienced surgeon from their own country. Usually, the onus falls upon the medical tourist to scour the Internet for clues about the competency of a foreign physician and the conditions of an overseas medical facility.

Having a physician intimate with the details of Canada's health care system also facilitates a smoother transition back into that system upon return. Physicians tend to be less than enthusiastic about providing postoperative care to patients returning from surgical centres in farflung corners of the world. After all, they may have received substandard care from inexperienced surgeons, which could result in poor outcomes or complications such as infection.

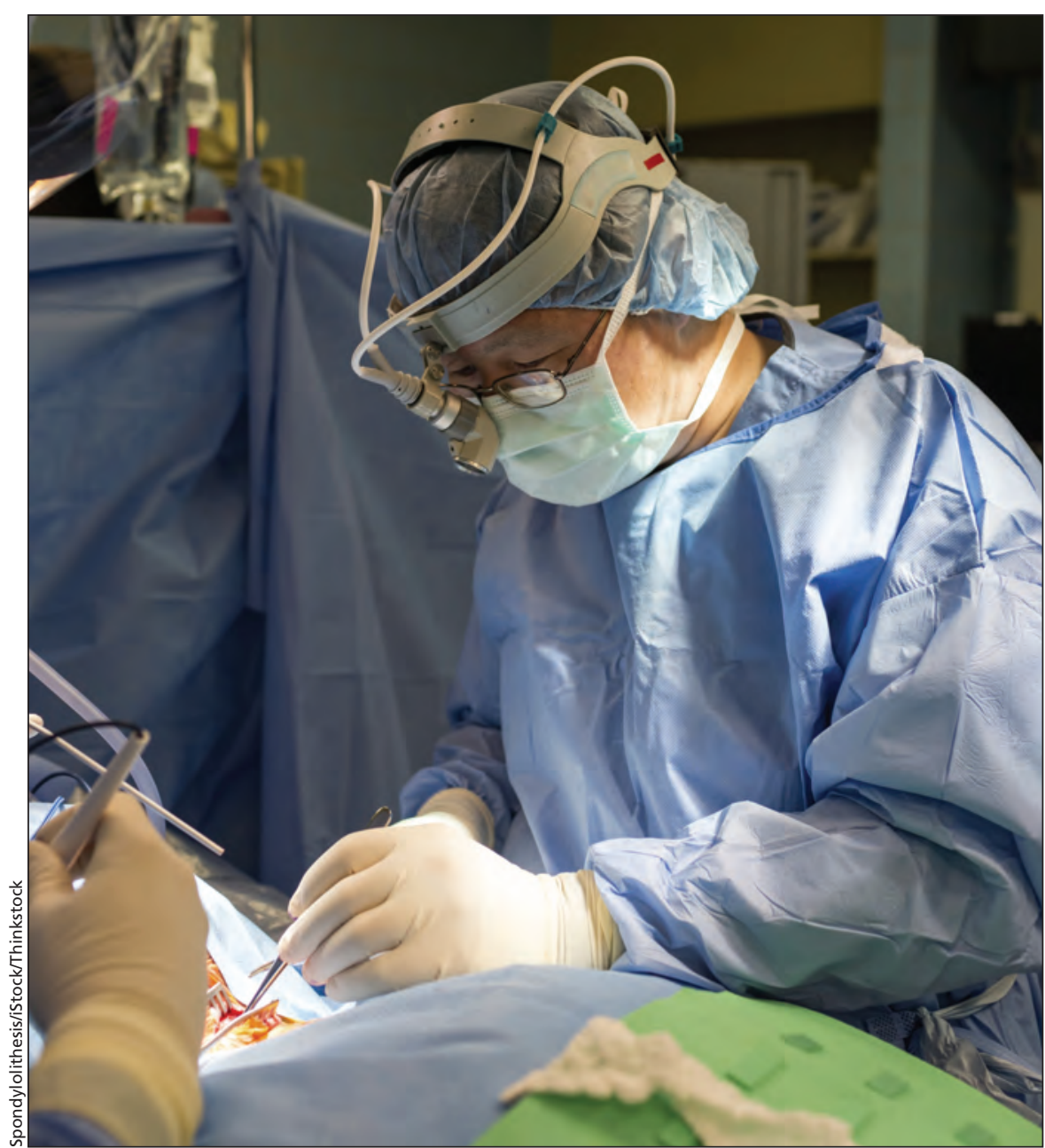

Some Canadian surgeons are operating on their patients in the Turks and Caicos to avoid long wait times at home.

The Calgary physicians who operate in Turks and Caicos perform some surgeries on their own patients, and can therefore provide follow-up care themselves when back on Alberta soil.

As for the benefit to Canadian surgeons, they have no real financial incentive to ply their trade in the Caribbean, says Boddington, because they aren't paid any more for procedures than in the Canadian system. Rather, much like wait-listed patients living in pain, the doctors are frustrated by limited access to operating rooms.

"From a Canadian physician perspective, it's being able to offer their patients another option," says Boddington.

Most of Global MedChoices clients are Canadian or American. In the 18 months that Global MedChoices has been operating, it has provided more than 50 procedures - in a three-year-old, stateof-the-art facility — and has reported no complications, says Boddington.

A large incentive for Canadian patients is timely access to procedures that could take up to a year or more to receive at home. The company's wait time for knee, hip or shoulder surgery is $6-12$ weeks. Factoring in medical costs with airfare and accommodations, the cost can be in the neighbourhood of $\$ 40000$, according to the Calgary Herald.

Lengthy wait times aren't as big a problem for US patients, who primarily choose Global MedChoices for financial reasons. On average, says Boddington, the company charges $25 \%$ $40 \%$ less than American providers of the same services. He anticipates a steady increase in demand for his com- 
pany's services among Americans, considering the US' massive baby boomer population, which is far more physically active than previous generations and shows no sign of slowing down with age.

"If you look at total knee replacements, the number is anticipated to increase exponentially over the next 20 years," says Boddington. "You are going to have not enough surgeons and too many patients, and those patients are going to be active. It is going to be a huge problem."

Though Harvey acknowledges that the Global MedChoices model provides timely access to good surgeons, he says the practice is not without consequences. Follow-up will still be more complicated than for procedures performed in Canada, he says, and that can have an impact on provincial health budgets.

"If this is a recurring event, and people are getting complicated health care outside the province and coming back, it has repercussions on the budget for post-op care, for complications and other things," he says.

If medical tourists end up needing emergency procedures after returning home, they will be bumped to the top of the queue, which could be perceived as unfair to those still waiting for their initial procedures. Malpractice laws also tend to be weaker in some popular medical tourism destinations, limiting recourse for patients who receive substandard care. And then there are the well-known dangers of travelling soon after surgery, such as increased risk of deep vein thrombosis.

It's possible, however, that skipping the queue in Canada could prove beneficial to the patients still in it. But because there are so few medical tourists, there is as yet no evidence one way or the other, says Jeremy Snyder, an associate professor of health sciences at Simon Fraser University in Vancouver, British Columbia, and a member of a medical tourism research group.

"If people find something ethically problematic about it, it would usually be the health equity point, the general idea that this is facilitating two levels of access," says Synder. "But some people might reasonably disagree with that, saying it is not necessarily making things worse for the people left behind. It's definitely a live debate."

\section{Sign of a broken system}

Regardless of how heated that debate becomes, the fact that doctors and patients are boarding airplanes to gain access to operating rooms speaks to a bigger problem, says Harvey - a broken Canadian health care system.

Unfortunately, he says, there is so much stigma around tinkering with the health care system in Canada, especially if private delivery is mentioned, that few dare even to broach the topic.

The operating rooms in hospitals typically sit empty 16 hours a day, he notes. What if private surgeons, with their own support and cleaning staff, were permitted to rent that space from early evening until midnight? The hospital would get more money and patients would have more choices. This is but one idea, suggests Harvey, though it and other ideas are unlikely to be taken seriously by provincial governments, reluctant as they are to explore new models of delivering care.

"I feel for the patients," he says. "This strict adherence to governmentbased health care is wrong for Canada. We've got longer wait lists and more unhappy customers."

Indeed, wait times only show signs of increasing further in some provinces. Take Quebec, for instance. There are 1379 orthopedic patients in the province who have been waiting at least six months for hip or knee surgery, reports the Montreal Gazette, and some have been waiting for more than a year. Montréal alone has some 400 patients who have waited more than half a year for joint replacements.

"This week, a lady came in for a hip replacement. She showed me a letter from the hospital saying she could not make a surgery appointment for two years," says Dr. Nicolas Duval, who runs a private orthopedic clinic in Montréal. "I could hardly believe it."

Duval opted out of medicare in 2002 , becoming the country's first private orthopedic surgeon. In general, though, the private delivery of orthopedic services in Canada is limited by provincial laws. An orthopedic surgeon in British Columbia, Dr. Brian Day, who runs a private clinic, is part of a lawsuit before the BC Supreme Court that is challenging such restrictions.

The cost for a hip or knee replacement at Duval's clinic, which performs about 400 surgeries a year, is $\$ 18000$. The wait time can be as little as two weeks and rarely exceeds six weeks. Many of his patients, similar to those who fly to the Caribbean, don't want to linger in the public queue, though some older patients go private for fear of catching a hospital-acquired infection at a larger facility.

Like Harvey, Duval thinks operating rooms in Canada are underused. If hospitals opened them for even two hours more a day, that would mean five more surgeries a week. There was a time, he notes, when banks also closed early, but they have changed their ways to meet demand. Yet for various reasons - politics, bad optics, increased costs - Canadian hospitals haven't followed suit.

Access to operating-room time is so limited, in fact, that many orthopedic surgeons can't find work. According to Duval, there will soon be more than 150 unemployed orthopedic surgeons in Canada. If this deters medical students from pursuing the specialty, it could eventually mean even longer delays for Canadian orthopedic patients.

Provincial governments are "too stubborn" to try something new to improve access, such as a better mix of public and private options, says Duval. And on the rare occasion when there is political will to address a pressing issue, it generally only results in a shift of resources from one area to another. A push to reduce queues for hip and knee replacements, for example, may result in longer wait times for patients who need foot or shoulder surgery.

Likewise, suggests Duval, medical tourism is not the solution to Canada's wait-time woes.

"To me, it's ridiculous that our own surgeons are flying to other countries to operate on our own patients," he says. "The only way to make a step forward is to do something different. Are we all going to ask our surgeons to fly to Turks and Caicos once a year to solve our problem?" - Roger Collier, CMAJ

CMAJ 2014. DOI:10.1503/cmaj.109-4722 